\title{
Modelling and planning urban mobility on long term by age-cohort model
}

\author{
Zoran Krakutovski ${ }^{1,}$, Darko Moslavac $^{1}$, Zlatko Zafirovski $^{1}$ \\ ${ }^{1}$ University Ss. Cyril and Methodius, bul. Partizanski odredi, 24, 5601000,Skopje, Macedonia
}

\begin{abstract}
The modelling and planning of urban mobility on long term is a very complex challenge. The principal sources for analysis of urban mobility are surveys made on particular period of time, usually every ten years. If there are minima two surveys carried out on different period it is possible to make a pseudo-longitudinal data using demographic variables as an age and generation. The temporal modifications of behaviour of population concerning the practice of urban daily mobility are possible to assess using a pseudo-longitudinal data. The decomposition of temporal effects into an effect of age and an effect of generation (cohort) makes possible to draw the sample profile during the life cycle and to estimate its temporal deformations. This is the origin of the "age-cohort" model to forecast the urban mobility on long term. The analysis and investigated data from three surveys of urban mobility are related to the urban area Lille in France.
\end{abstract}

\section{Introduction}

The urban transport planning and traffic forecast is traditionally carried out using an algorithm in four steps or known as an aggregated traffic model. This model assesses trip generation (production and attraction of trips), trips distribution from and to each studied zone, modal split of trips and route assignment of motorised trips [1]. Each output from previous step is input for next modelling process. Nevertheless, this model is problematic when the transport demand should be projected on long term. The principal contestation concerns the usage of data collected only on a particular date. This means that the forecasting of urban mobility on long term is based on static methodological approach. The social, economic, and demographic modifications are difficult to identify using data from one survey. The forecasting of urban mobility on long term needs longitudinal data to enter in the dynamic of behaviour changes.

The demographic model "age-cohort" is pertinent to introduce the behaviour modifications of different generations living in certain urban area. The consideration of demographic variables in the model enables to taking into consideration the dynamic of behaviour on long term.

\footnotetext{
*Corresponding author: krakutovski@gf.ukim.edu.mk
} 


\section{Particularities of mobility and demographic analysis}

\subsection{Available data for mobility analysis}

The first stage of the traditional aggregated traffic model concerns the assessment of generation of trips or the total number of generated and attracted trips in each particular zone. The explicative variables habitually used in this first step of modelling are demographic and socio-economic variables related to the characteristics of residents or households and activities of population in studied zones. The principal source for analysis of urban mobility is the specific surveys made with representative sample of households living in considered urban area. The urban mobility surveys "households - trips" are standardised in France according to the CERTU methodology.

The studied area in this paper is the urban agglomeration of Lille in France where are considered three surveys made in 1976, 1987 and 1998.

The three existing surveys give a possibility to analyse the mobility through two different approaches. The mobility can be analysed using available data of each survey separately. The following three variables are analysed to assess the behaviour towards mobility from 1976 to 1998 :

- average number of trips per individual and per day,

- travel budget-time which is total time to make daily trips per individual and

- travel budget-distance which is total distance of daily trips per individual

The pattern of average number of trips per individual and per day according to three mobility surveys and by age range is showed on the next figure.

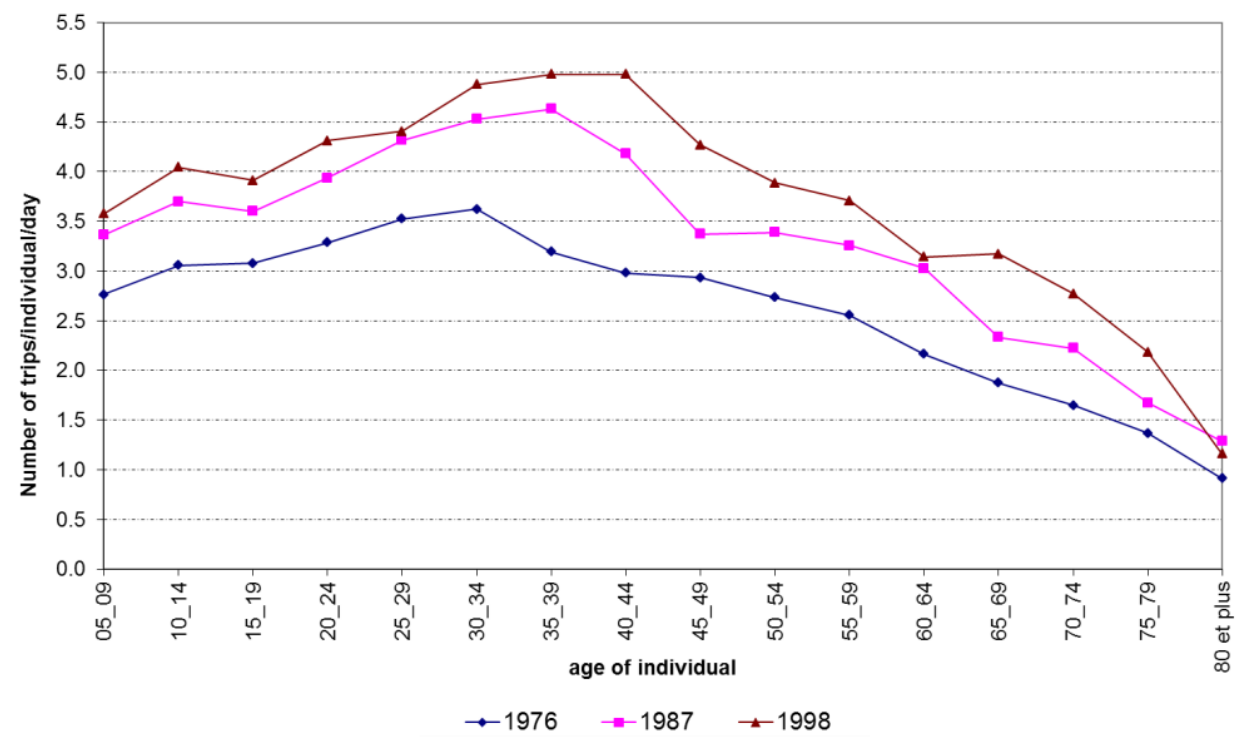

Fig.1. Number of trips/individual/day and per age range according to three mobility surveys data.

The mobility measured by number of trips per individual per day increases for each age range from 1976 to 1998. This pattern shows also that age of individual is very important characteristics towards urban mobility. The age effects are more important in the middle of life cycle while they are smaller in the oldest age range. The similar patterns are for the budget-time and for budget-distance.

The following table with aggregated data shows the changes of behaviour toward urban 
mobility of citizens in urban agglomeration of Lille. It is important to note that the perimeter of studied urban area is similar to the perimeter in the first survey in 1976.

Table 1. Changes of daily mobility in Lille according to three surveys.

\begin{tabular}{|c|c|c|c|}
\hline \multirow{2}{*}{ Year of survey } & \multicolumn{3}{|c|}{ Mobility variable } \\
\cline { 2 - 4 } & $\begin{array}{c}\text { Number of } \\
\text { trip/indiv./day }\end{array}$ & $\begin{array}{c}\text { Budget-time } \\
\text { (min./indiv./day) }\end{array}$ & $\begin{array}{c}\text { Budget-distance } \\
\text { (km/indiv./day) }\end{array}$ \\
\hline 1976 & 2.83 & 50.8 & 5.6 \\
\hline 1987 & 3.60 & 51.0 & 7.4 \\
\hline 1998 & 4.01 & 57.0 & 8.8 \\
\hline
\end{tabular}

This previous data reveals that the mobility increases permanently in the period from 1976 to 1998.

\subsection{Characteristics of demographic analysis}

The demography includes the study of the size, structure and distribution of populations living in certain area and spatial or temporal changes concerning the demographic particularities as a birth, migration, ageing and death. The analyses and demographic assessments are closely linked to the following factors:

- age, which in a historical perspective measures the time spent since the birth of an individual until the date of behaviour observation,

- cohort or generation of birth of an individual,

- period of observation or the date of identification of the studied phenomenon.

Highlighting the importance of time in demographic analyses, or splitting the time by its components, can be realized using a longitudinal analysis. The evolutions are displayed through the resultant of two components, a static and a dynamic. The first focuses on the existence of a permanent regime that is expressed by a standard profile over the life cycle and the second reflects the historical evolution by using the generational gaps. The longitudinal data make possible to enter into history of generations. This type of analysis requires observations deployed in time which is a difficult characteristic to be fulfilled for certain studies.

The German statistician Lexis offers already in 1875, an original graph to display simultaneously on the same diagram the relationships between three dimensions: time (or period), age of individuals (position in the life cycle) and generation (or cohort) of birth [2](Fig. 2). The person's life is represented in the Lexis diagram by a straight line called "life line". This representation permits seeing the difference between transversal and longitudinal data. The time is presented only by the age of individuals in the case of analysis based on a transversal data. The usage of longitudinal data enables the measurement of time by age (in line) and also a historical measurement of time (in column). The observations corresponding to same generation appear on the diagonal crossing the age of individuals and year of observation. The cohort can be defined as a group of persons who experience an event in the same time period, e.g., birth, marriage. The Lexis diagram can show the experience of a certain cohort in a particular age interval (a) and it can also show the experience of a cohort as they move through life cycle. 


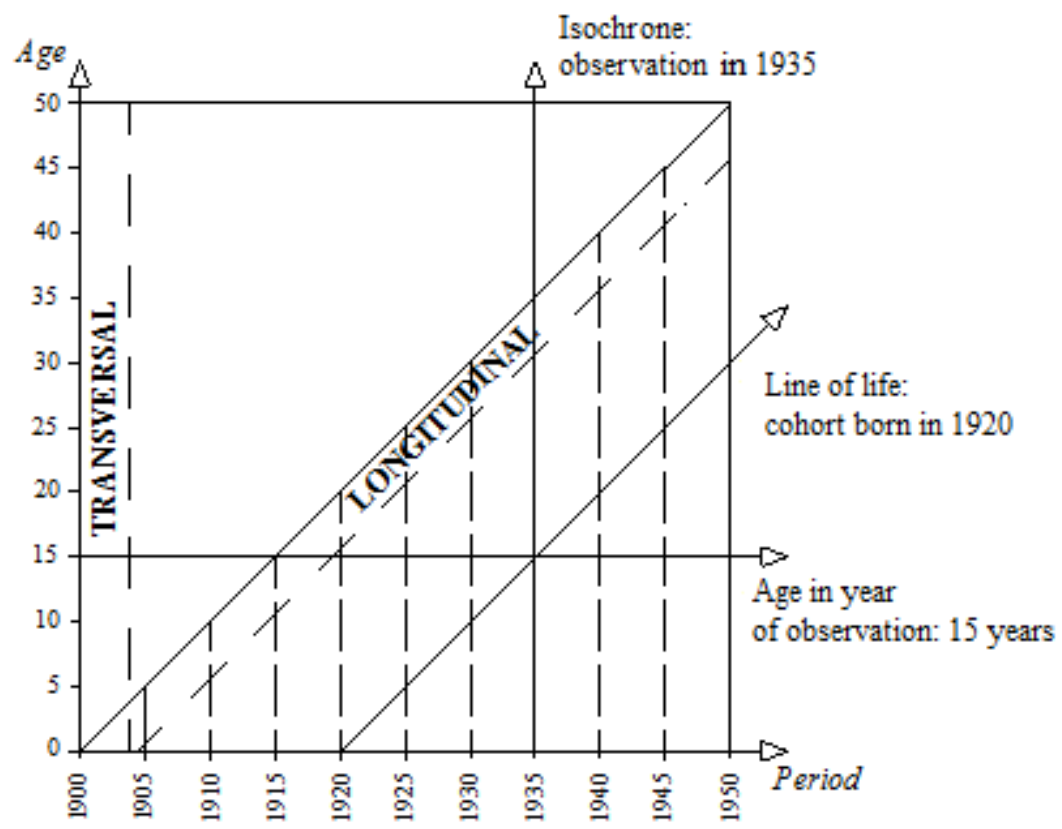

Fig.2. Diagram of Lexis-Becker-Pressat [2].

\subsection{Making of longitudinal data}

The demographic approach exploits data from repetitive surveys from different dates, which makes possible to get insight in the behaviour dynamics [2]. The main sources for studying and forecasting mobility are standardized household surveys directed to identify the mobility determinants of population at a certain date. These surveys contain large heterogeneity regarding the age and generations of individuals [5] but also they offer possibility to identify individuals belonging to the same cohort or generation of birth. Between the observation period (p), the individual's age (a) and the generation of birth (cohort $\mathrm{c}$ ) there is the following relationship:

$$
c=p-a
$$

Therefore, it is possible to create longitudinal data (pseudo-panel) from mobility surveys made in different periods. The three surveys "Household-Trips (EMD), standard CERTU" made in Lille (North of France) in 1976, 1987 and 1998 (Table 2) are the main sources to study the urban mobility and to create a longitudinal data which will be used for mobility forecast (Table 3) [6].

Table 2. Samples size of the three surveys.

\begin{tabular}{|l|c|c|c|}
\hline \multirow{2}{*}{ Type of questionnaire } & \multicolumn{3}{|c|}{ Size of survey } \\
\cline { 2 - 4 } & 1976 & 1987 & 1998 \\
\hline Households & 9804 & 3465 & 3744 \\
\hline Individuals (age>5years) & 27005 & 8345 & 8454 \\
\hline Internal trips & 76383 & 29967 & 33907 \\
\hline Total trips & 79948 & 31969 & 35804 \\
\hline
\end{tabular}


Table 3. Longitudinal data created according to the three surveys.

\begin{tabular}{|l|l|l|l|l|l|l|}
\hline $\begin{array}{c}\text { Year of birth } \\
\text { (cohort) }\end{array}$ & \multicolumn{2}{|l|}{ Survey 1976 } & \multicolumn{2}{l|}{ Survey 1987 } & \multicolumn{2}{l|}{ Survey 1998 } \\
\cline { 2 - 7 } & Age & Size & Age & Size & Age & Size \\
\hline Before 1895 & $82 \&+$ & 444 & & & & \\
\hline $1895-1905$ & $71-81$ & 1807 & $82 \&+$ & 159 & & \\
\hline $1906-1916$ & $60-70$ & 2603 & $71-81$ & 519 & $82 \&+$ & 150 \\
\hline $1917-1927$ & $49-59$ & 3485 & $60-70$ & 832 & $71-81$ & 526 \\
\hline $1928-1938$ & $38-48$ & 3842 & $49-59$ & 1039 & $60-70$ & 793 \\
\hline $1939-1949$ & $27-37$ & 4032 & $38-48$ & 1111 & $49-59$ & 958 \\
\hline $1950-1960$ & $16-26$ & 5403 & $27-37$ & 1520 & $38-48$ & 1418 \\
\hline $1961-1971$ & $05-15$ & 5389 & $16-26$ & 1661 & $27-37$ & 1350 \\
\hline $1972-1982$ & & & $05-15$ & 1504 & $16-26$ & 1835 \\
\hline $1983-1993$ & & & & & $05-15$ & 1424 \\
\hline
\end{tabular}

\section{Demographic model for analysing and forecasting of urban mobility}

\subsection{Analysis of mobility through longitudinal data}

The analysis of mobility of inhabitants in Lille is made using a longitudinal data. The three following variables are analysed: number of trips per day and per inhabitant, travel budgettime and travel budget-distance. The longitudinal data shows the impact of different generations for mobility changing (Figure 3, Figure 4, Figure 5).

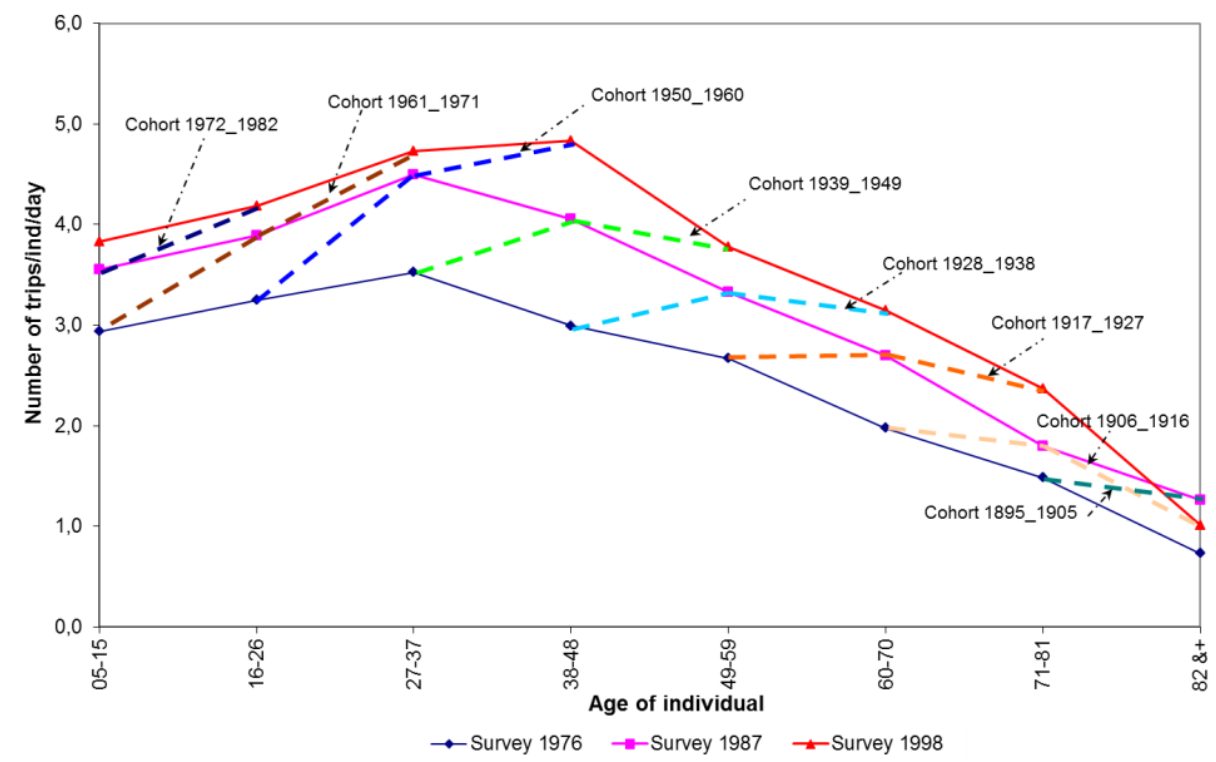

Fig.3. Number of trips/person/day by age group and cohort in the three surveys. 


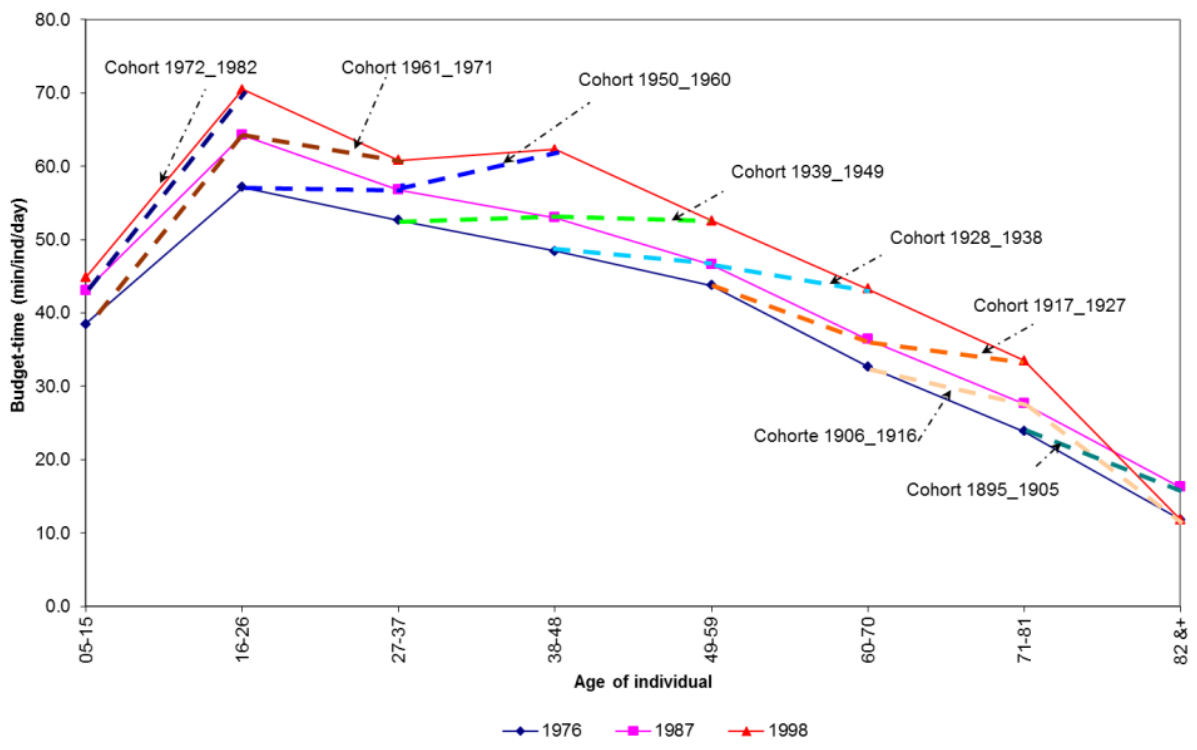

Fig.4. Budget-time by age group and cohort in the three surveys.

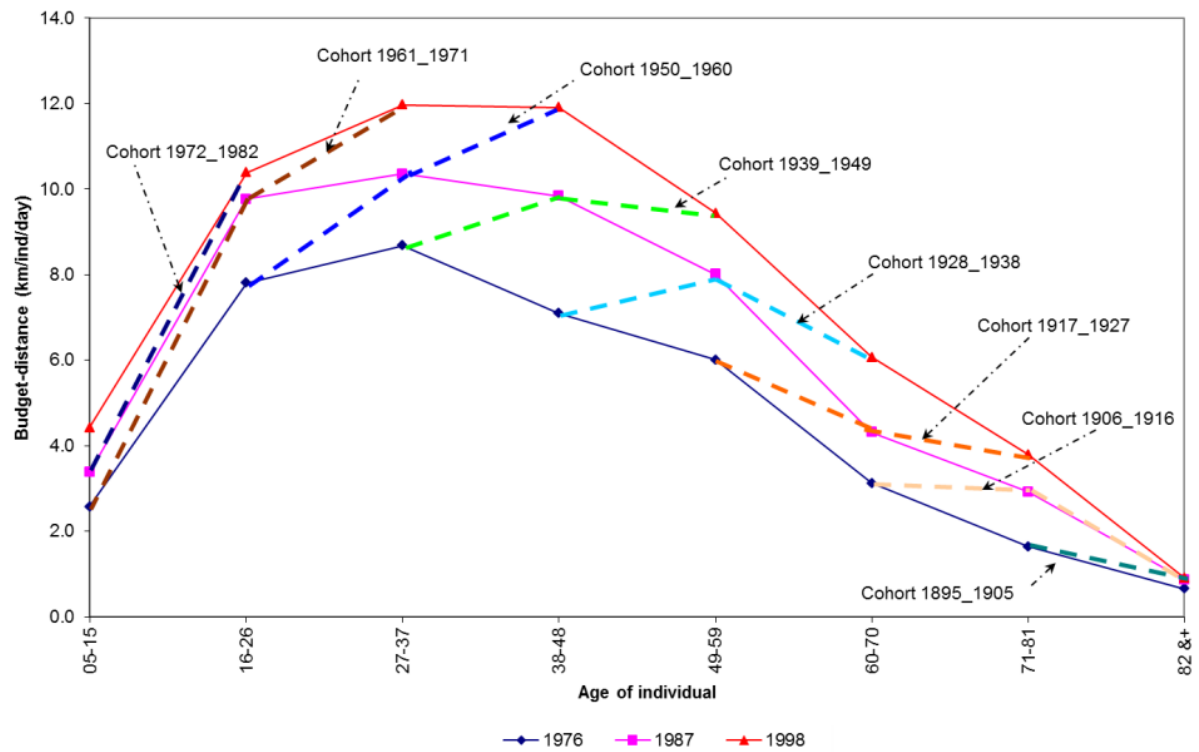

Fig.5. Budget-distance by age group and cohort in the three surveys.

The difference between the curves of different cohorts at any given age can be interpreted as the cohort effect. This approach allows creating "age-cohort" model which is pertinent to forecast mobility on long term [5]. 


\subsection{Model age-cohort for analysis and forecast of urban mobility}

The application of the model for mobility projections requires separating the projections of population and the projections of mobility behaviours. Therefore, the general structure of a demographic model contains two main parts [4]:

- the first part includes the estimations of population and

- the second part concerns the mobility modelling and estimation of a standard profile during the life cycle.

The demographic model for forecast of urban mobility will be particularly interested with changes in a human population, as well as projections of their numbers and structure in a given geographical space. So, the first part of estimations of population is done by "OMPHALE" model developed by INSEE. This model makes possible to project on longterm the population by gender and age in an area constituted by one or some municipalities. The minimum number of population per area for which estimations are possible is more than 50000 inhabitants.

The second part of the model concerns the mobility analysis and forecast which is possible according to the longitudinal data [3]. The effects of period, or the impact of the factors affecting all individuals on the particular date, could be neglected if the stability of these effects is delicate. The decomposition of temporal effects makes possible to trace the sample profile during the life cycle and to estimate its temporal deformations. The data from three surveys enable assessing the mobility for a certain number of observed cohorts. The effects of age on urban mobility could be described by a curve called „standard profile of life-cycle" for reference cohort (Figure 6). The "age-cohort" model estimates this standard profile by age. The fundamental assumption is that all deformations of this standard profile are caused by the effects of cohorts.

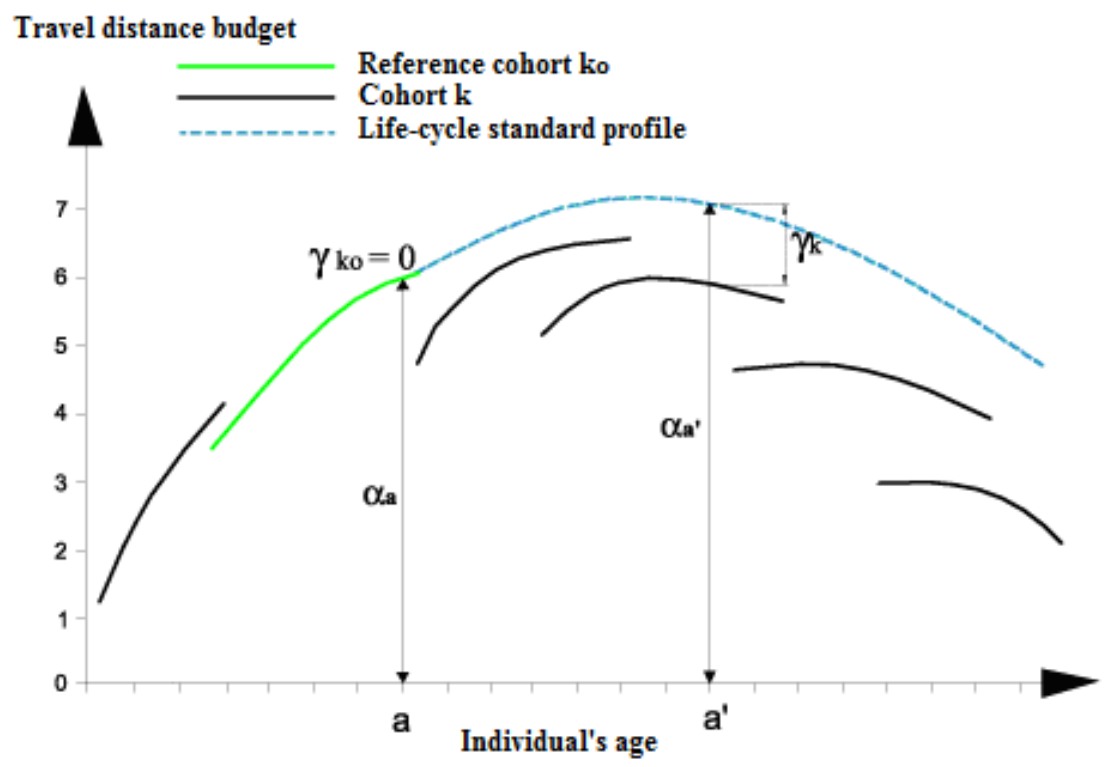

Fig.6. Principle for specification of "age-cohort" model.

The mathematical expression of the "age-cohort" model is as follows:

$$
M_{a, k}=\alpha_{a(k o)} A_{a}+\gamma_{k} C_{k}+\varepsilon_{a, k}
$$


Where $\mathrm{M}_{\mathrm{a}, \mathrm{k}}$ is a measure of mobility behavior (daily budget-distance, number of trips per day and per individual,...) observed at age "a" of individuals belong to cohort " $k$ ", $\alpha_{a(k o)}$ is a measure of mobility behavior at age "a" for individual of the reference cohort "ko" which allows to calculate a standard profile of the life cycle, $\gamma_{k}$ is difference in the trajectory of each cohort " $k$ " relative to the curve for the reference cohort "ko" $\left(\gamma_{\mathrm{ko}}=0\right.$ for the reference cohort "ko"), A and C are dummy variables for "age" and "cohort", $\varepsilon_{\mathrm{a}, \mathrm{k}}$ is an error term in the model.

\section{Comments concerning mobility forecasting}

Firstly, the model provides estimations of the parameters of variables age and cohort. These results refer to the curve of standard profile of life cycle and the difference between the cohorts. Then, in the second step, the model uses projections of the population to create future cohorts whose gaps regarding the cohort of reference are not yet observed. The gaps observed between the penultimate cohort and those preceding it are added to the new cohorts. The technique of distinction and addition of the two effects makes possible to estimate mobility behaviour up to the fixed horizon.

The projections of mobility based on growth factors are also conducted which is a method commonly used in aggregate models of passenger demand.

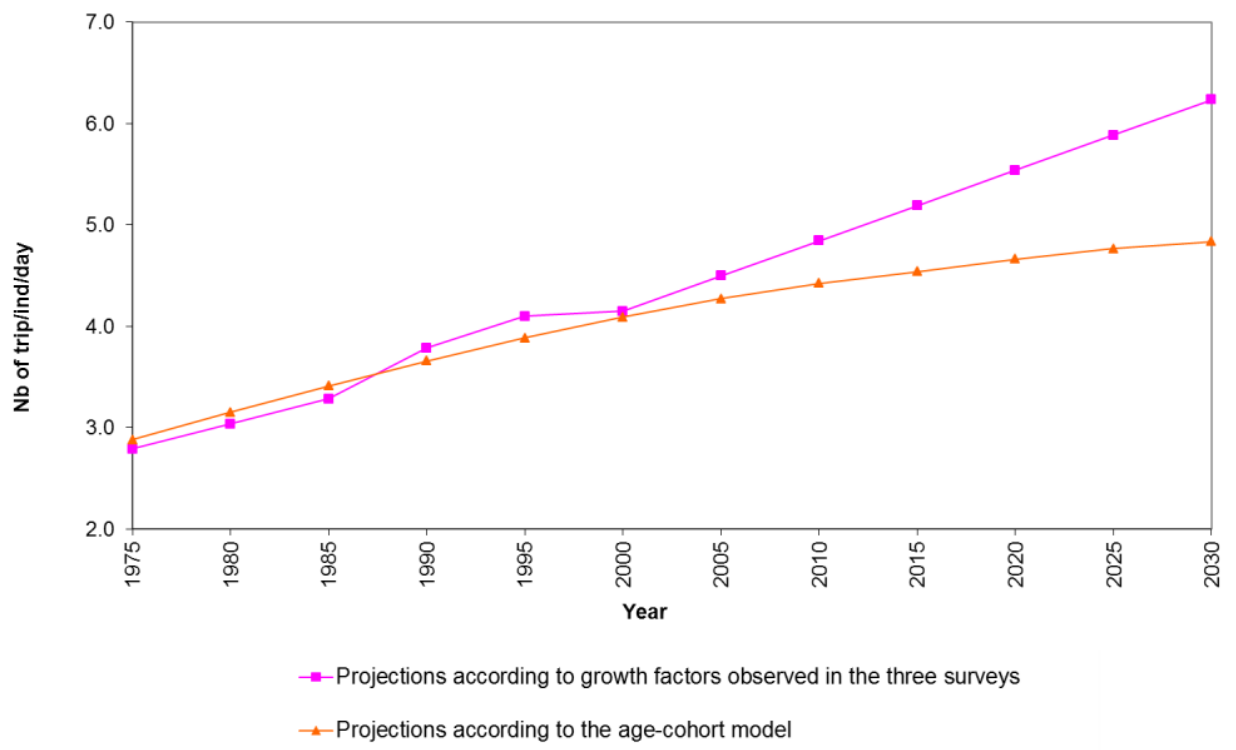

Fig.7. Projections of number of trips per individual and per day according to growth factors and the model age-cohort. 


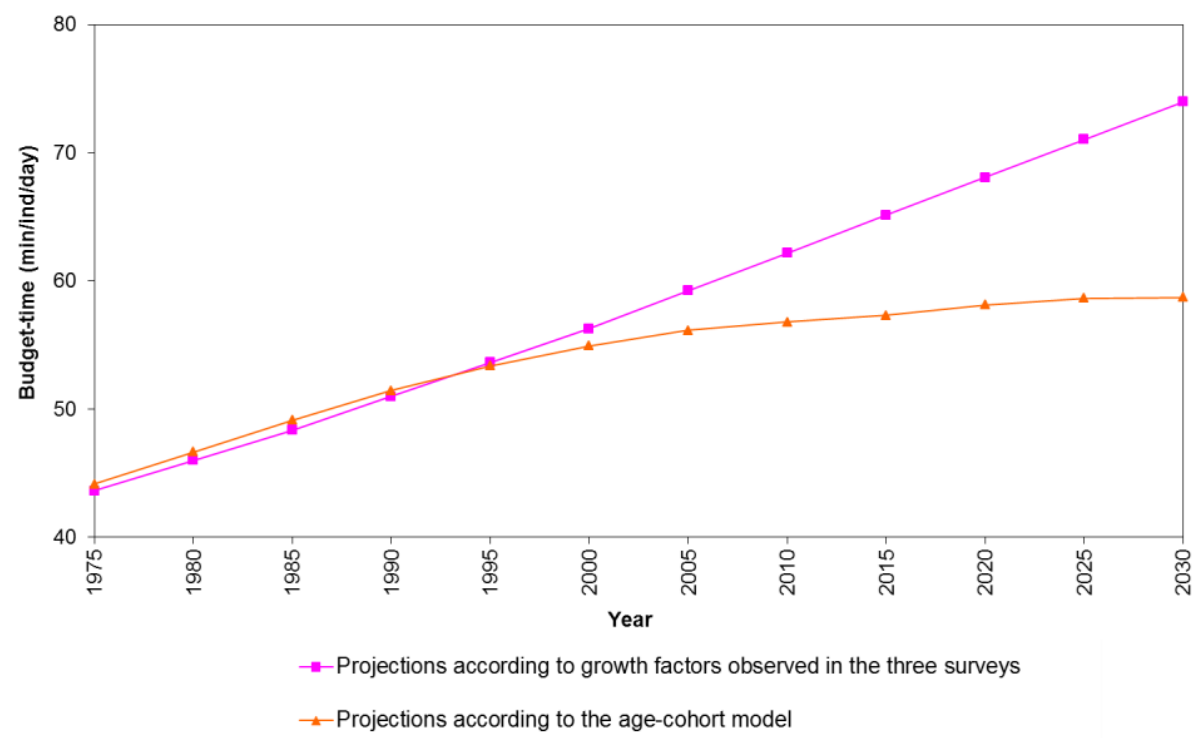

Fig.8. Projections of budget-time according to growth factors and the model age-cohort.

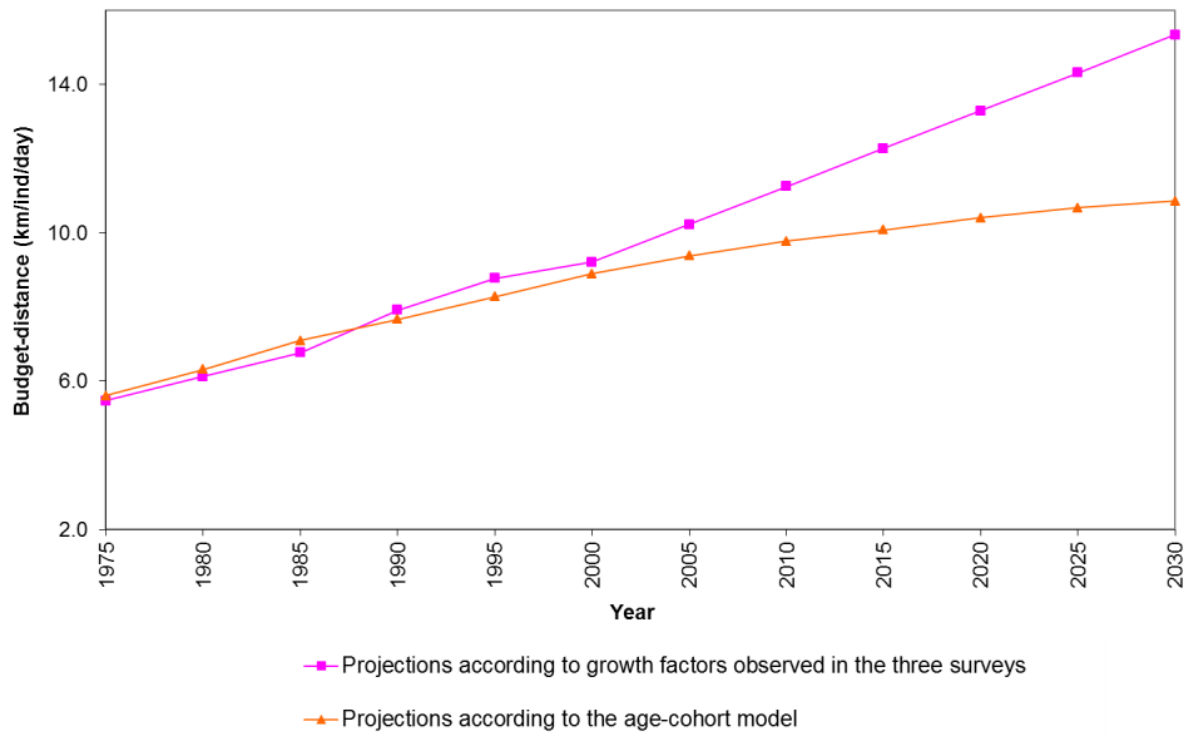

Fig.9. Projections of budget-distance according to growth factors and the model age-cohort.

The estimated results according to the demographic model age-cohort are lower than those obtained according to the projections by the growth factors and seem more realistic.

\section{Conclusions}

The age-cohort model is possible using if we dispose of pseudo-panel created from several surveys made in different periods. The demographic variables are very suitable for long term projection because they keep a big inertia concerning important changes in long period. 
The projections of mobility in urban agglomeration of Lille are made until 2030. The analysis and projections of mobility indicate that the usage of cars increases the daily distances but in same time the progression of budget-time is marginal. This trend gives the impression that the benefit of car travel time is converted into extra daily distances. The projections of mobility by the age-cohort model are significantly lower than the projections made using a growth factors derived from transversal data. The insertions of cohort effects in the model influence long-term projections decreasing effects of growth factors.

The validation of forecasts is made using two methods:

- Confidence interval concerning the data in the three surveys and the forecast results. The level of confidence chosen is $95 \%$.

- Linear regressions between estimations and observations of mobility in surveys data. The regressions indicate that the $\mathrm{R} 2$ is about 1 , the slope is not significantly different from 1 , and the intercept is not significantly different form 0 .

The validation of model projections is satisfactory for the two audit criteria which mean that the "age-cohort" model resumes correctly the observed behaviour in the past. The main weakness of the age-cohort model is that this model recommends a long-term evolution scenario that seems be unique and unavoidable. The absence of economic factors in the modelling such as income of the individual or the prices of transport modes avoids their respective roles in the projections. However, the projections of economic factors on long term also present many difficulties and risks [10].

\section{References}

1. M. McNally, Four Step Model, (University of California, 2007)

2. C. Louis, Le destin des générations, (Presses Universitaires de France, Paris, 2002)

3. B.Yve, M. Jean-Loup, L'Harmattan, Démographie et transport: villes du Nord et villes du Sud ", (L'Harmattan, Paris 2002)

4. C. Gallez, Modèles de projection à long terme de la structure du parc et du marché de l'automobile, $\mathrm{PhD}$ Thesis, (1994)

5. Z. Krakutovski, Amélioration de l'approche démographique pour la prévision à long terme de la mobilité urbaine, $\mathrm{PhD}$ Thesis, (2004)

6. Z. Krakutovski , J. Armoogum, INED, Population, 62(4), 759-786 (2007)

7. K. Krizek, P. Waddel, Analysis Of Lifestyle Choices: Neighbourhood Type, Travel Patterns, And Activity Participation, (University of Minnesota, 2001)

8. P.L. Mokhtarian, C. Chen, Modelling Individual's Travel Time And Money Expenditures (University of California, Davis,2000)

9. R. Moffitt, Journal of Econometrics, 59, 99-123 (1993)

10. F. Papon, J. Armoogum, J. Madre, M. Massot, Prospective de la mobilité en Île-deFrance: Les apports et les limites d'une démarche économétrique, (INRETS-DEST, Paris, 2001)

11. J. Armoogum, J. Madre, B. Yves, IATSS RESEARCH 33(2), 9-20 (2009) 